\title{
Characteristics of Carbon Fiber Composite Current Collector Used in Proton Exchange Membrane Fuel Cell
}

\author{
Chong-Kai Wang ${ }^{1}$ and Yean-Der Kuan ${ }^{2 *}$ \\ ${ }^{1}$ Intelligent Machinery and Smart Manufacturing, National Chin-Yi University of Technology, \\ Taichung City 411, Taiwan \\ ${ }^{2}$ Department of Refrigeration, Air-Conditioning and Energy Engineering, National Chin-Yi University \\ of Technology, Taichung City, 411, Taiwan
}

(Received June 5, 2021; accepted November 9, 2021)

Keywords: proton exchange membrane fuel cell, carbon fiber composite, current collector, carbonization

The main aim of this study is to use a carbon fiber composite board to replace the traditional graphite board. Because a carbon fiber composite has high mechanical strength and corrosion resistance and other desirable properties, we fabricate it into a current collector for use in a fuel cell. We use phenolic resin and flake graphite powder combined with carbon fiber plain weave to fabricate the carbon fiber composite current collector, which is carbonized in a high-temperature furnace at $800{ }^{\circ} \mathrm{C}$. In this method, the resin, which has poor conductivity, is removed to increase the conductivity of the current collector. The electrical conductivity is measured using a fourpoint probe surface resistance machine and the flexural strength is measured using a universal material testing machine. In addition, the same characteristics of carbon fiber composite materials fabricated with different carbonization times are then discussed. Finally, the carbon fiber composite current collectors are assembled in single cells for performance testing.

\section{Introduction}

Current collectors play an important role in fuel cells. They should have the functions of transmitting gaseous fuel, conducting electricity, and dissipating heat. ${ }^{(1)}$ Traditionally, they have been fabricated of metal or graphite. Although metal current collectors have good electrical conductivity and ductility, their corrosion resistance is poor, reducing their service life. Current collectors made of graphite have good conductivity and corrosion resistance, but their stress strength is low, which causes problems in their production and use. Carbon fiber composites have good mechanical strength and corrosion resistance, but because the resin in the composites is a poor conductor, their conductivity is poor. To improve the conductivity of carbon fiber composites, we can add a conductive powder or remove the resin. Kuan et al. used carbon nanotube powder added to phenolic resin to coat a carbon fiber cloth and a high-temperature furnace to carbonize a carbon fiber bipolar plate at $600{ }^{\circ} \mathrm{C}$. They showed that a fuel cell with a carbon fiber bipolar plate assembly carbonized three times has excellent performance superior to

*Corresponding author: e-mail: ydkuan@ncut.edu.tw https://doi.org/10.18494/SAM.2021.3702 
that of a fuel cell with a graphite current collector. ${ }^{(2)}$ Kakati et al. added conductive particles such as natural graphite and carbon black to phenolic resin. The mixed solution was added to carbon fibers to fabricate carbon fiber composites by heatpressing. The natural graphite and carbon black form a conductive channel, thereby increasing conductivity. ${ }^{(3)} \mathrm{Li}$ et al. fabricated a current collector by adding different proportions of expanded graphite powder and phenolic resin, with added resin contents of 15, 20, and 25\%. They showed that the higher the resin content, the lower the corrosion rate, and the lower the resin content, the higher the mechanical strength. ${ }^{(4)}$ Resin is the main reason for the poor conductivity of carbon fiber composites. Therefore, in previous studies, high-temperature carbonization or ion etching was performed to remove phenolic resin and increase the conductivity of carbon fiber composites. Kim et al. used propane and acetylene to carbonize carbon fiber composite plates at temperatures of 1000 and $3000{ }^{\circ} \mathrm{C}$, respectively. They found that the longer the carbonization time, the lower the surface contact resistance. However, the permeability of the current collector increased and the mechanical strength decreased with increasing carbonization time.(5) Nair et al. conducted experiments on different types of phenolic resins such as maleimide functional and novolac resins. The resins all had the same residual carbon content under the experimental conditions of $700{ }^{\circ} \mathrm{C}$ carbonization for $2 \mathrm{~h}$ and $900{ }^{\circ} \mathrm{C}$ carbonization for $2 \mathrm{~h} .{ }^{(6)}$ Di et al. etched a carbon fiber composite board in a solution of chromium trioxide and sulfuric acid. As the temperature and time increased, some carbon fibers were exposed on the surface of the board. They found that the resistivity of a carbon fiber composite material can be improved by immersing it in the etching solution at $70{ }^{\circ} \mathrm{C}$ for $15 \mathrm{~min} .{ }^{(7)}$ Lee et al. used the soft layer method to remove resin from the surface of a composite material to expose the fibers, thereby reducing the contact resistance. A tighter fiber arrangement requires a higher pressure $(20 \mathrm{MPa})$ to effectively squeeze the resin, while a pressure of only $3 \mathrm{MPa}$ is required for a looser fiber arrangement. ${ }^{(8)}$ In this study, we developed a carbon fiber current collector for use in proton exchange membrane fuel cells. The current collector has high conductivity, corrosion resistance, and mechanical strength. In the following, we described the materials, production process, and test method of our carbon fiber current collector.

\section{Materials and Methods}

\subsection{Matrix}

Carbon fiber composite materials are composed of a matrix and a reinforcement material. Common matrix materials are epoxy and phenolic resins. Resins can be divided into thermosetting resins and thermoplastic resins according to their curing characteristics. The former are liquid at room temperature that solidify when they reach their curing temperature, whereas the latter are solid at room temperature and become plastic when exposed to heat, hence their name. In this study, the phenolic resin shown in Fig. 1 was used as the matrix and the curing temperature was $150{ }^{\circ} \mathrm{C}$. 


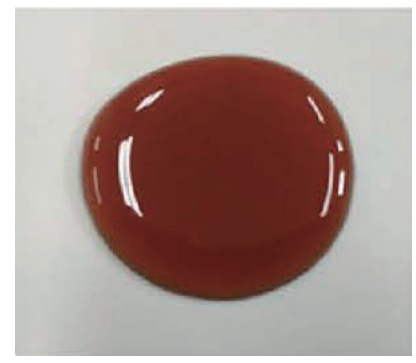

Fig. 1. (Color online) Phenolic resin.

\subsection{Reinforcement material}

In this study, we used carbon fiber plain weave as the reinforcement material of the carbon fiber composite. Carbon fibers have high strength and temperature resistance. Each carbon fiber is composed of thousands of smaller carbon fibers with a diameter of about 5-8 $\mu \mathrm{m}$. The plain weave was fabricated by interweaving the warp and weft yarns upward and downward. A carbon fiber cloth is shown in Fig. 2.

\subsection{Conductive particles}

A carbon fiber cloth has good conductivity in the horizontal direction because the interwoven carbon fibers form conductive paths. However, the poor conductivity of the resin will hinder the transmission of electrons and increase the resistance. Therefore, it is necessary to add a conductive substance to the resin to form a conductive channel between the layers to increase the conductivity in the vertical direction. In this study, flake graphite powder was added to the resin to increase the conductivity. The flake graphite powder is shown in Fig. 3.

\section{Experimental Process}

\subsection{Production of carbon fiber composite board}

The carbon fiber cloth was cut to an appropriate size. The weights of the resin and flake graphite powder were based on the weight of the carbon fiber cloth. A homogenizer with a rotation speed of $480 \mathrm{rpm}$ was used to uniformly mix the methanol-added phenolic resin and flake graphite powder, where methanol was added to reduce the viscosity of the phenolic resin to facilitate uniform mixing. The production of the carbon fiber prepreg is shown in Fig. 4. We used a spatula to coat the evenly mixed solution on the carbon fiber cloth, which was then left to dry. We cut the carbon fiber cloth to the size of the mold and stacked it layer by layer. When stacking, a roller was used to squeeze out the air. The stacked carbon fiber prepreg was placed in a mold, then sent to a heat pressing machine for heat pressing. The pressure, temperature, and time used for heat pressing were $150 \mathrm{~kg} / \mathrm{cm}^{2}, 150{ }^{\circ} \mathrm{C}$, and $30 \mathrm{~min}$, respectively. The heat pressing process is shown in Fig. 5. After the heat pressing process was completed, the thus fabricated 


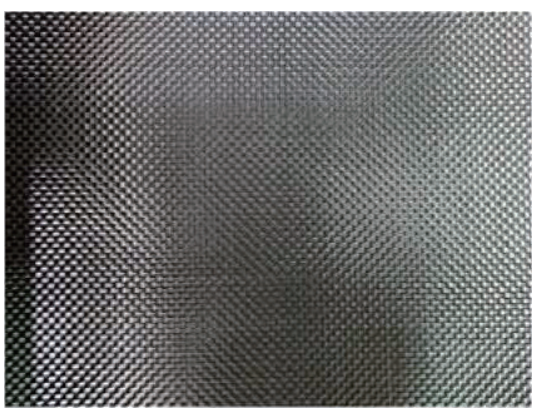

Fig. 2. Carbon fiber cloth.
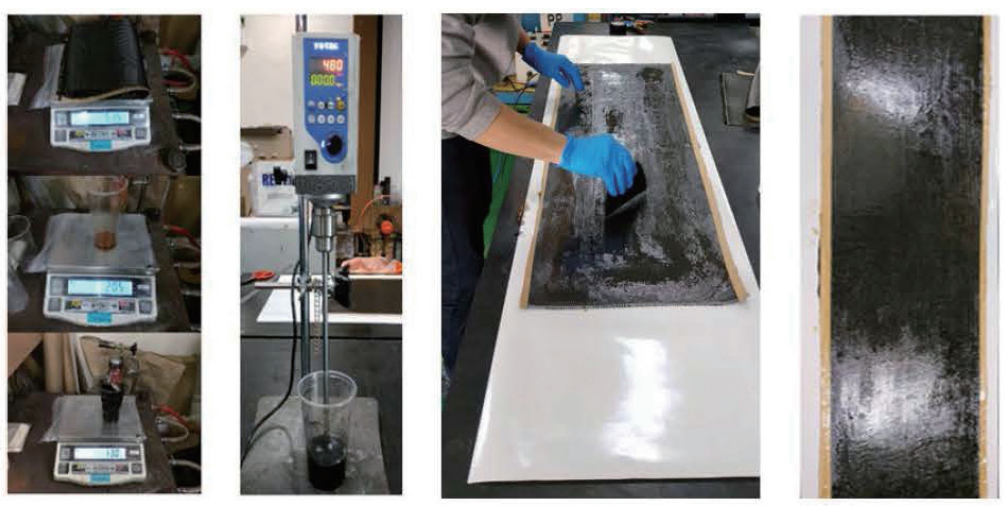

Fig. 4. (Color online) Production of carbon fiber prepreg.

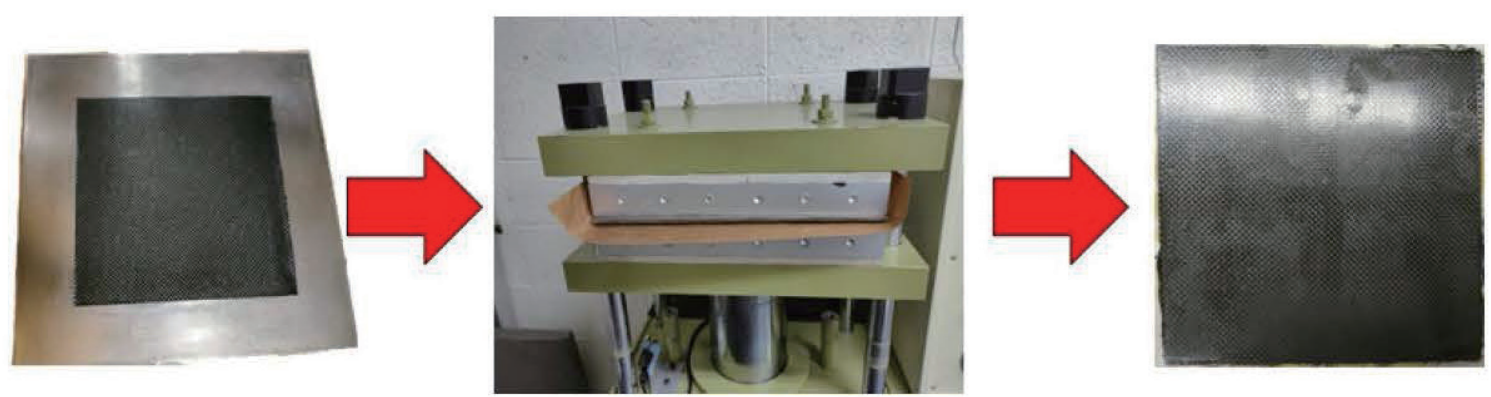

Fig. 5. (Color online) Heat-pressing process.

carbon fiber composition board was removed from the machine and left to cool to room temperature.

\subsection{Production of carbon fiber composite current collectors}

The shape and size of the current collector were drawn using AutoCAD. A CAD file was imported into the engraving software to set the engraving path. Then, we sent the file to a computer numerical control (CNC) engraving and milling machine for engraving to form the 
carbon fiber composite current collector shown in Fig. 6. To improve its conductivity, the current collector was placed in a high-temperature furnace filled with nitrogen for carbonization. The carbonization temperature used in this study was $800{ }^{\circ} \mathrm{C}$ and the carbonization time was $30 \mathrm{~min}$. The carbonization process is shown in Fig. 7. After carbonization, the collector was removed from the furnace and left to cool. Increasing the number of carbonizations can further increase the conductivity of the current collector. Therefore, the current collector was repeatedly soaked in the resin then heat-pressed as described above.

\subsection{Stress tests}

A universal material testing machine was used for mechanical strength testing, and flexural stress tests were performed on test pieces that had been carbonized 0-3 times in accordance with the ASTM D790 specifications. ${ }^{(9)}$ The test pieces had a length of $130 \mathrm{~mm}$, a width of 13 $\mathrm{mm}$, and a thickness of $2.5 \mathrm{~mm}$. The universal material testing machine and test pieces are shown in Fig. 8.

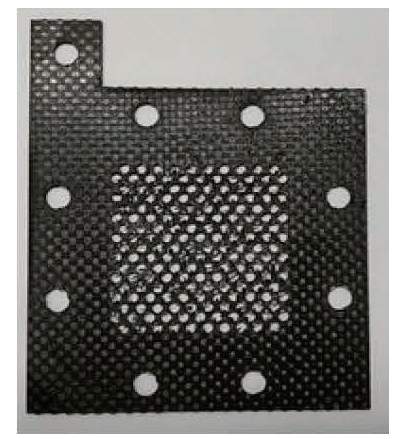

Fig. 6. Carbon fiber composite current collector.

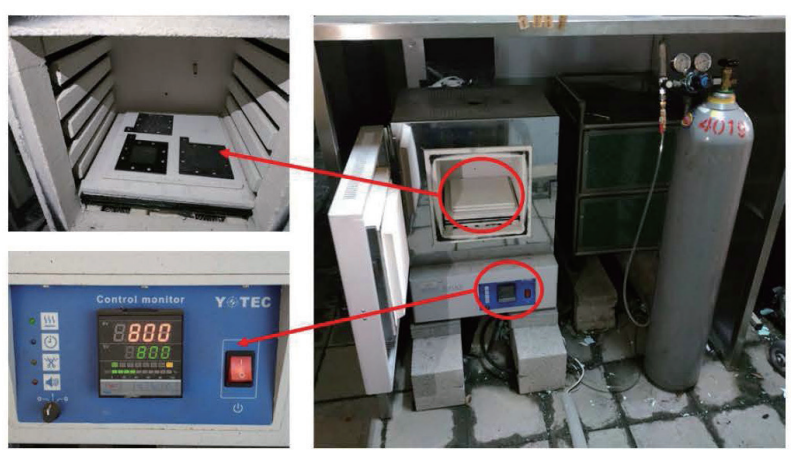

Fig. 7. (Color online) Carbonization process.

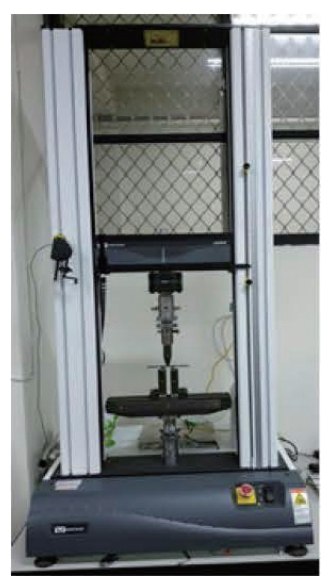

(a)

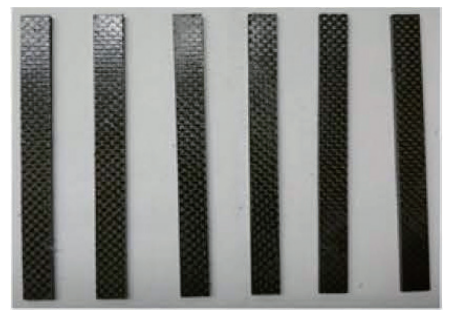

(b)

Fig. 8. (Color online) (a) Universal material testing machine and (b) test pieces. 


\subsection{Surface resistance tests}

In this study, the surface resistances of the carbon fiber composite current collectors were measured using the four-point probe surface resistance testing machine shown in Fig. 9. The unit is ohm per square $(\Omega / \mathrm{sq})$. Current collectors with different carbonization times were measured at 10 points to observe the effect of carbonization on their surface resistance.

\subsection{SEM images}

We performed thermal field-emission scanning electron microscopy (FE-SEM) to observe the surface of the carbon fiber board. From the SEM image, we could observe the distributions of phenolic resin and flake graphite powder on the carbon fibers before and after carbonization.

\subsection{Fuel cell performance test}

We evaluated the performance of the single fuel cell with the carbon fiber composite current collector shown in Fig. 10. The composite current collector was carbonized 0-3 times. During the performance test, the anode supplied hydrogen with a flow rate of $300 \mathrm{sccm}$, the cathode supplied oxygen with a flow rate of $600 \mathrm{sccm}$, the gas was humidified and heated to $50{ }^{\circ} \mathrm{C}$, and the load was applied by a constant voltage. The related data were measured using voltage and current sensors, and then performance curves were drawn for further analysis.

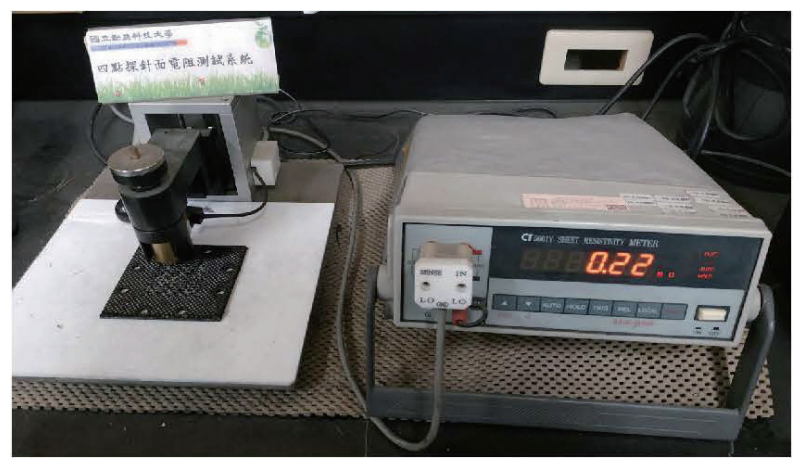

Fig. 9. (Color online) Four-point probe surface resistance testing system.

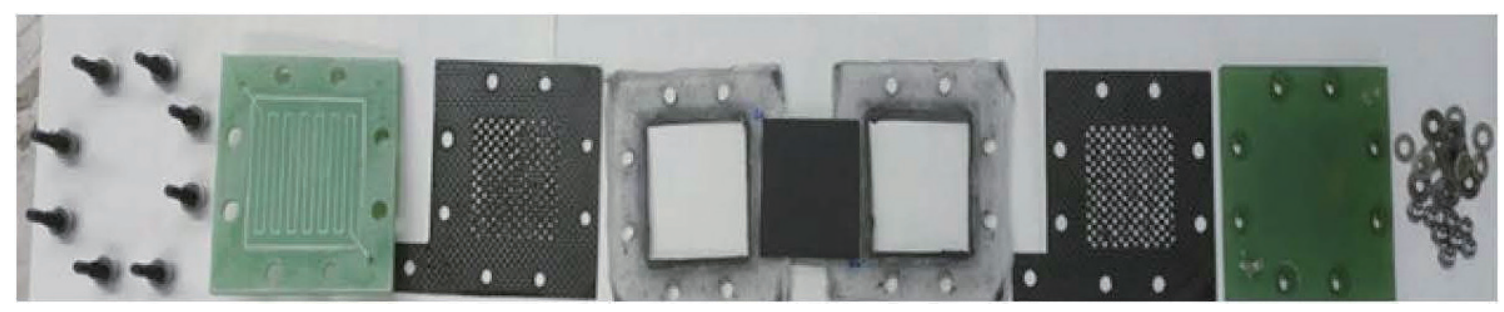

Fig. 10. (Color online) Exploded image of fuel cell with carbon fiber composite current collector. 


\subsection{Performance test of pasted copper current collector}

We examined the effect of conductive paths on the back of the carbon fiber composite current collector on the performance of the fuel cell. To achieve this, copper foil tape was attached to the back of the carbon fiber composite current collector. An exploded image of the fuel cell with the carbon fiber composite current collector and back-pasted copper is shown in Fig. 11. The performance test was the same as that in Sect. 3.6 and was carried out with a closed or open end plate, where the open end plate was open on the cathode side and the oxygen participating in the reaction was taken naturally from air.

\section{Results}

The results of the flexural strength test are shown in Table 1. According to the results, the uncarbonized carbon fiber composite board has the largest stress. As the number of carbonizations increases, the flexural stress decreases. The stress of the carbon fiber composite board with 0 to 3 carbonizations exceeds $25 \mathrm{MPa}$, meeting the US Department of Energy (DOE) 2020 target. ${ }^{(10)}$ However, the average stress of the carbon fiber composite plate specimens carbonized twice is lower than that of the specimens carbonized three times. It is speculated that

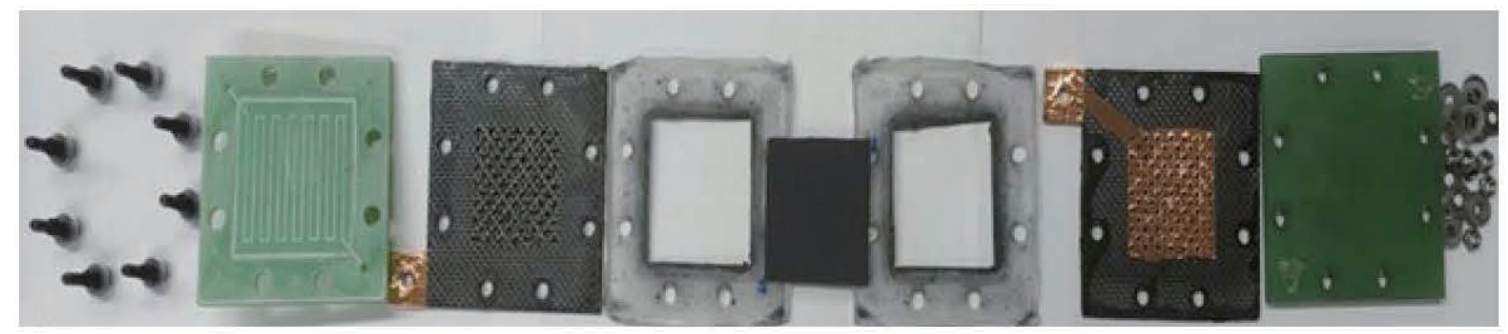

Fig. 11. (Color online) Exploded image of fuel cell with carbon fiber composite current collector and back-pasted copper.

Table 1

Maximum flexural strengths of current collectors.

\begin{tabular}{lcccc}
\hline Test No. & $\begin{array}{c}\text { Uncarbonized } \\
(\mathrm{MPa})\end{array}$ & $\begin{array}{c}\text { One carbonization } \\
(\mathrm{MPa})\end{array}$ & $\begin{array}{c}\text { Two carbonizations } \\
(\mathrm{MPa})\end{array}$ & $\begin{array}{c}\text { Three carbonizations } \\
(\mathrm{MPa})\end{array}$ \\
\hline 1 & 467.5 & 73.5 & 34.2 & 53.6 \\
\hline 2 & 448.2 & 68.7 & 47.5 & 38.6 \\
\hline 3 & 497.2 & 63.5 & 40.6 & 39.9 \\
\hline 4 & 452.9 & 62.4 & 33.0 & 45.6 \\
\hline 5 & 482.8 & 50.84 & 51.3 & 60.4 \\
\hline Average & 397.2 & 69.3 & 38.3 & 38.4 \\
\hline
\end{tabular}


this is because the carbon fiber composite plate is repeatedly immersed in phenolic resin, which increases its stress strength. The results of four-point probe surface resistance measurements are shown in Table 2. According to the results, the surface resistance of the uncarbonized carbon fiber current collector is the highest. As the number of carbonizations increases, the surface resistance decreases. SEM images of the carbon fiber board obtained before and after carbonization are shown in Fig. 12. According to the SEM images, the surface of the carbon fiber composite board before carbonization is covered with phenolic resin. The carbon fibers on the surface of the carbon fiber composite board are exposed after carbonization, and the flake graphite powder is distributed between the fiber layers. The results of the performance tests are shown in Fig. 13. The uncarbonized carbon fiber composite current collector has the lowest performance, and the performance improves with the number of carbonizations. The carbon fiber composite current collectors carbonized two and three times have similar performance characteristics; thus, it is speculated that the best performance can be achieved by performing carbonization twice. The performance test results of the current collector with back-pasted copper show that increasing the back-side conductivity can improve the performance. The closed cell has higher performance characteristics than the open cell as shown in Fig. 14. This is because the closed cell supplies oxygen, whereas the open cell draws oxygen from air owing to the difference in oxygen density.

Table 2

Surface resistances of carbon fiber composite current collectors. (Unit: $\mathrm{m} \Omega / \mathrm{sq}$ )

\begin{tabular}{lrrrrrrrrrr}
\hline \multirow{2}{*}{ Test sample } & \multicolumn{10}{c}{ Test point } \\
\cline { 2 - 12 } & 1 & 2 & 3 & 4 & 5 & 6 & 7 & 8 & 9 & 10 \\
\hline Uncarbonized & 312.01 & 280.53 & 299.76 & 356.39 & 320.54 & 203.39 & 236.54 & 285.43 & 312.57 & 331.24 \\
\hline One carbonization & 88.56 & 277.88 & 99.43 & 107.36 & 141.21 & 142.55 & 177.51 & 154.63 & 114.79 & 90.51 \\
\hline Two carbonizations & 42.78 & 32.08 & 46.54 & 36.79 & 46.24 & 36.41 & 32.08 & 44.51 & 47.85 & 30.02 \\
\hline Three carbonizations & 46.18 & 55.41 & 43.15 & 46.56 & 44.26 & 33.98 & 34.52 & 43.65 & 44.79 & 32.41 \\
\hline
\end{tabular}

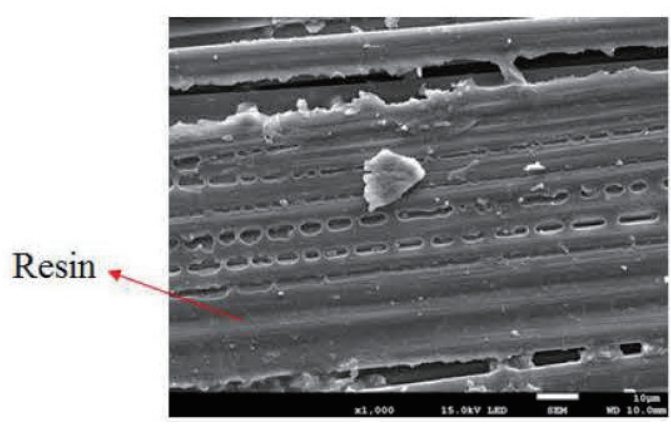

(a)

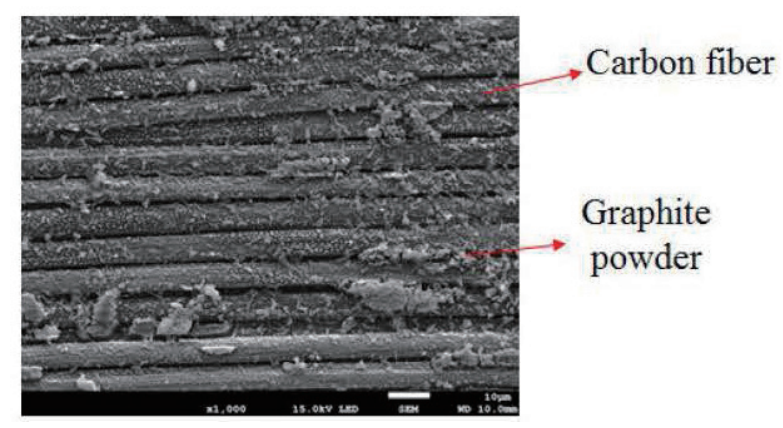

(b)

Fig. 12. (Color online) SEM images obtained (a) before and (b) after carbonization. 


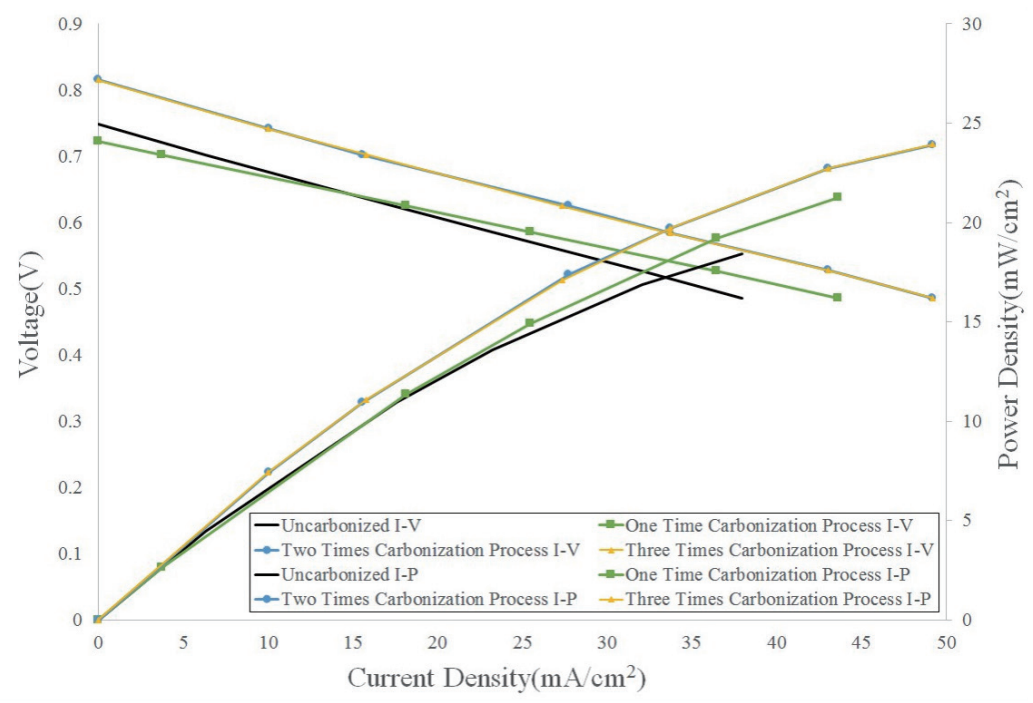

Fig. 13. (Color online) Performance characteristics of carbon fiber composite current collectors after different numbers of carbonizations.

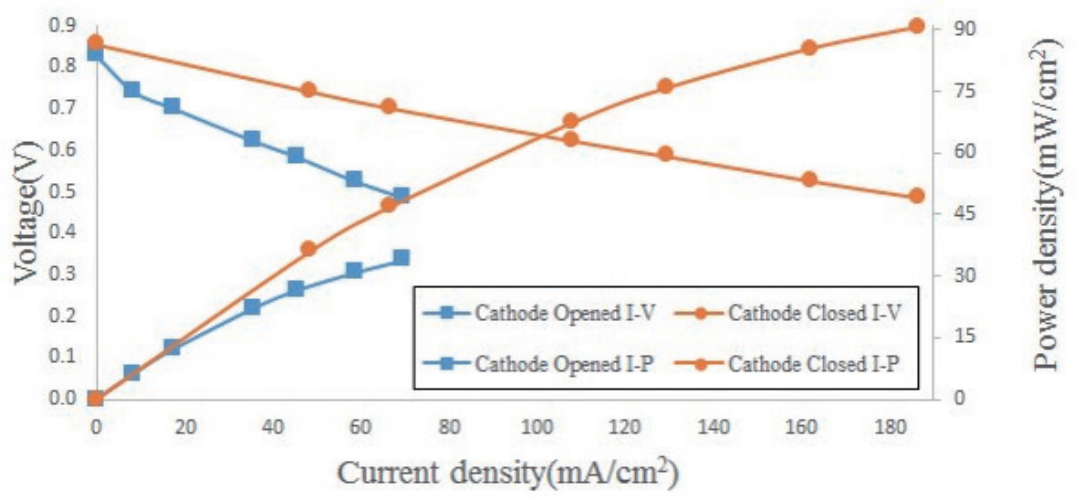

Fig. 14. (Color online) Performance characteristics of fuel cells with opened and closed cathodes.

\section{Conclusion}

We developed planar carbon-fiber-based fuel cell current collectors, which were assembled in single-cell proton exchange membrane fuel cells to experimentally evaluate their performance characteristics. It was found that carbonization strongly affected the characteristics of the current collectors. The performance of the current collector carbonized twice was the same as that of the current collector carbonized three times, meaning that two carbonizations were sufficient for the carbon fiber composite current collectors. By pasting the back of a current collector with copper, it was shown that increasing the conductivity of the back of the current collector can improve its performance. 


\section{Acknowledgments}

The authors sincerely acknowledge the support by the Ministry of Science and Technology of Taiwan (MOST 109-2221-E-167-006).

\section{References}

1 M. W. Ellis, M. R. Von Spakovsky, and D. J. Nelson: Proc. 2001 IEEE Fuel Cell Systems: Efficient, Flexible Energy Conversion for the 21st Century (IEEE, 2001) 1808.

2 Y. D. Kuan, C. K. Wang, C. Yang, P. C. Lee, Y. S. Siao, and C. Y. Lee: Sens. Mater. 32 (2020) 4233.

3 B. K. Kakati, D. Sathiyamoorthy, and A. Verma: Int. J. Hydrogen Energy 35 (2010) 4185. https://doi. org/10.1016/j.ijhydene.2010.02.033

4 W. Li, S. Jing, S. Wang, C. Wang, and X. Xie: Int. J. Hydrogen Energy 41 (2016) 16240. https://doi.org/10.1016/j. ijhydene.2016.05.253

5 M. Kim, J. W. Lim, K. H. Kim, and D. G. Lee: Compos. Struct. 96 (2013) 569. https://doi.org/10.1016/j. compstruct.2012.09.017

6 C. P. Reghunadhan Nair, R. L.Bindu, and K. N. Ninan: Polym. Degrad. Stab. 73 (2001) 251. https://doi. org/10.1016/S0141-3910(01)00076-3

7 L. Di, B. Liu, J. Song, D. Shan, and D. A. Yang: Appl. Surf. Sci. 257 (2011) 4272. https://doi.org/10.1016/j. apsusc.2010.12.035

8 D. Lee, J. Choe, S. Nam, J. W. Lim, I. Choi, and D. G. Lee: Compos. Struct. 160 (2017) 976. https://doi. org/10.1016/j.compstruct.2016.10.107

9 ASTM INTERNATIONAL: Standard Test Methods for Flexural Properties of Unreinforced and Reinforced Plastics and Electrical Insulating Materials, D790 (Annu. B. ASTM Stand., 2002) pp. 1-12. https://doi. org/10.1520/D0790-17.2

10 D.U.S. Department of Energy: Technical Targets for Polymer Electrolyte Membrane Fuel Cell Components (2020), https://www.energy.gov/eere/fuelcells/doe-technical-targets-polymer-electrolyte-membrane-fuel-cellcomponents (accessed October 2021).

\section{About the Authors}

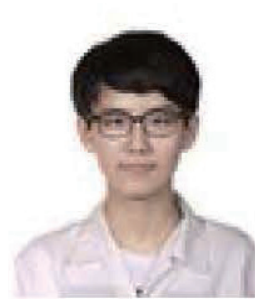

Chong-Kai Wang received his diploma degree from the Department of Refrigeration, Air-Conditioning and Energy Engineering, National Chin-Yi University of Technology (NCUT), Taiwan, in 2019, from which he received his master's degree in 2021. During his study, he focused on fuel cells and the procedure for fabricating carbon fiber composite boards. He is currently studying toward his Ph.D. degree at NCUT.

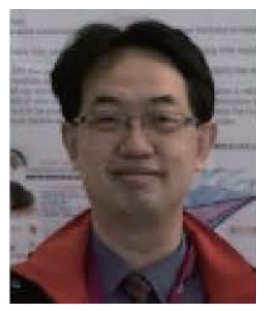

Yean-Der Kuan is a distinguished professor and former chair (2013/022019/01) of the Department of Refrigeration, Air-Conditioning and Energy Engineering at National Chin-Yi University of Technology, Taichung, Taiwan. He received his Ph.D. degree from the Department of Mechanical and Aerospace Engineering, University of Missouri, USA, in 2000. He is currently the director of the Taiwan Society of Heating, Refrigeration and Air Conditioning, the director of the Taiwan Energy Association, the director of the Taiwan Association for Hydrogen Energy and Fuel Cell, and a member of the American Society of Heating, Refrigerating, and Air-Conditioning. His research interests include the fields of energy-saving and renewable energies, and air-conditioning components and systems. 